\title{
Engaging diverse students with Crystallography Research
}

\section{Oluwatoyin A. Asojoa}

${ }^{a}$ Department of Chemistry and Biochemistry Hampton University 200 William R. Harvey Way Hampton VA 23668 oluwatoyin.asojo@hamptonu.edu

My objective is to share approaches by which I am incorporating structural biology into our biochemistry curriculum at an HBCU. I will also present methods that I use to engage $\mathrm{K}-12$ and undergraduate students in crystallographic research and structural biology (since 2001). I will discuss the successes and failures involved in the process of fully integrating these pre-baccalaureate students in crystallography research. Since some of our outreach efforts have included students that are socioeconomically underserved or from groups underrepresented in STEM, strategies for recruiting and retaining these students will also be discussed. Major barriers to our programs will be discussed, while potential funding sources will be shared. 